\title{
Research on CAN Communication of light Vehicle Driving Force Electronic Control System
}

\author{
Shaoyi Li \\ Nanchang Institute of Science \& Technology
}

Keywords: CAN; Light Vehicle; Driving Force Electronic System; Communication Protocol

\begin{abstract}
The driving force electronic control system composed of electronically controlled engine, automatic transmission and traction control system can realize the active regulation to the driving force, improve vehicle dynamic, trafficability and handling stability. CAN bus technology cannot only avoid the redundancy of wiring harness and sensor in the driving force electronic control system, but also can realize high speed, accurate, real-time communication. In this paper, the CAN bus development tool CANoe is adopted to develop driving force electronic control system CAN communication. According to the actual situation of the target vehicle, CAN communication network scheme is proposed, and based on the CAN2.0B technical specification and SAE J1939 protocol and system function demands, the detailed protocol of physical layer, data link layer and application layer are introduced. According to the formulation of communication protocols, the network database, model generation, programming communication function are constructed and the virtual instrument is established to carry out off-line simulation and verify the rationality and feasibility of communication protocols.
\end{abstract}

\section{Introduction}

With the development of vehicle technology and the electronic technology, the electronic control system which works independently originally gradually becomes interrelated, interdependence and has mutual influence, which realizes associated control to improve the performance of vehicles. However, taking driving force electronic control system which is composed of electronic controlled engine, automatic transmission and traction control system as an example, each controller needs to communicate with each other. The traditional wiring is complex and the signals interfere with each other, which makes it is difficult to meet the requirements of high-speed, accurate, real-time communication of the system and the traditional wiring also affects the control effect of driving force. Vehicle network is an important way to realize the communication requirements, and the Controller Area Network (CAN) communication in it has been widely used in vehicles due to the advantages of networking and functionality.

In this paper, the communication protocol is studied and developed. The combined control of engine output torque, transmission gear and driving wheel brake in driving force electronic control system is realized and a set of feasible development process according to driving force electronic control system CAN communication is put forward.

\section{Overview of CAN Bus Technology}

At present, there are more than $20 \mathrm{CAN}$ bus controller chip makers in the world and more than 110 kinds of CAN bus protocol controller chip and microprocessor chip integrated CAN bus protocol controller. The design of CAN gives full consideration to the bad working environment of vehicle with high reliability and its characteristics are as follows:

CAN bus is a multi master bus each node of which can send information to other nodes in the network at any time.

CAN bus adopts the unique non destructive bus arbitration technology, which sends date for high priority node, which can meet the real-time requirements.

CAN bus has the transmitting functions of point to point, point to multipoint and global broadcast. 
CAN bus adopts the short frame structure and the number of effective bytes per frame is up to 8 . The data transmission time is short and there are CRC and other verification measures which makes the data error rate be very low.

When a serious fault occurs on the CAN bus, the bus can be automatically separated from the bus, while the other operations on the bus are not affected.

During the extension of CAN bus system, the new node can be directly hung on the bus with a few wiring, which makes the system can easily be extended and flexibly modified.

The maximum transmission rate of CAN bus is up to $1 \mathrm{Mb} / \mathrm{s}$ (now the longest communication distance is $40 \mathrm{~m}$ ), and the direct communication distance is up to $10 \mathrm{~km}$ (with the rate below $5 \mathrm{Kbps}$ ).

Although the current domestic vehicle electronic control network technology has a certain gap comparing to the foreign advanced automotive electronics technology, with the deepening of research and the improvement of independent innovation capability, the gap will gradually decrease.

\section{Development of CAN communication protocol for driving force electronic control system}

CAN technical specification and CAN international standard are the fundamental basis for the design of CAN bus application system. CAN2.0 technical specification is divided into two parts, which are A and B. 2.0A specifies each definition of the standard frame with 11 bit identifier, while 2.0B specifies each definition of the extended frame with 29 bit identifier.

CAN communication protocol mainly describes the information transfer mode between equipment. the definition of CAN layer and open systems interconnection model (OSI) is consistent, as shown in Table 1. Each layer communicate the layer which is equivalent to another equipment. The actual communication occurs in the two adjacent layers of each equipment, while the equipment interconnects only through the physical media of the physical layer of the model.

Table 1

\begin{tabular}{|c|c|c|}
\hline $\begin{array}{l}\text { Layer } \\
\text { level }\end{array}$ & $\begin{array}{l}\text { ISO/OSI } \\
\text { layers }\end{array}$ & Function description \\
\hline 7 & $\begin{array}{c}\text { The } \\
\text { application } \\
\text { layer }\end{array}$ & $\begin{array}{l}\text { The highest layer which is used for information exchange among users, } \\
\text { software and network terminals }\end{array}$ \\
\hline 6 & $\begin{array}{c}\text { The } \\
\text { presentation } \\
\text { layer }\end{array}$ & $\begin{array}{l}\text { Transform two system information from two different data formats into a } \\
\text { format that can be shared together. }\end{array}$ \\
\hline 5 & $\begin{array}{l}\text { The session } \\
\text { layer }\end{array}$ & $\begin{array}{l}\text { Rely on the low level communication function to carry on the effective } \\
\text { transmission of data. }\end{array}$ \\
\hline 4 & $\begin{array}{l}\text { The transport } \\
\text { layer }\end{array}$ & $\begin{array}{l}\text { The data transmission control between the two communication nodes. } \\
\text { Operations such as data retransmission, data error repair }\end{array}$ \\
\hline 3 & $\begin{array}{l}\text { The network } \\
\text { layer }\end{array}$ & $\begin{array}{l}\text { Protocol providing the establishment, maintenance and removal of a } \\
\text { network connection, such as: routing and addressing }\end{array}$ \\
\hline 2 & $\begin{array}{l}\text { The data link } \\
\text { layer }\end{array}$ & $\begin{array}{l}\text { Provide the arrangement and organization of the data bits that are } \\
\text { transmitted on a medium, such as data check and frame structure. }\end{array}$ \\
\hline 1 & $\begin{array}{l}\text { The physical } \\
\text { layer }\end{array}$ & $\begin{array}{l}\text { Provide the physical characteristics of the communication media, such as } \\
\text { the electrical characteristics and the interpretation of the signal exchange. }\end{array}$ \\
\hline
\end{tabular}

CAN specification defines the two bottom layers of the model: data link layer and physical layer. CAN mainly adopts the network structure with three layers: physical layer, data link layer and application layer. There are three different devices corresponding to the layer in the device. The layer corresponding physical layer is CAN transceiver whose the main function is to encoding and decoding, bit timing and synchronization. The layer corresponding data link layer is CAN controller whose the main function is data transmission and remote data service requests, filtering and overload notification and recovery management. In the application layer, it is the user's special application and the corresponding device is Microprocessor Control Unit (MCU). 


\section{The Driving Force Electronic control System CAN Communication Program}

The hardware and software of the electronic throttle design has been completed, the next is to test the communication, control effect and response. The completed electronic throttle nodes can be connected to the simulation bus of CANoe. Semi-physical simulation is used to test the performance and the special process as follows: Firstly, disconnect the connection of the electronic throttle simulation nodes and simulation bus in canoe simulation model and keep other connections between simulation nodes and simulation bus, which is shown in Fig. 5.10. In the figure, electronic throttle simulation node DAC_ECU are connected, which shows that the node disconnects with the simulation bus system. Connect accelerate pedal with true electronic accelerator nodes and to the actual bus. Then, connect the actual bus to the simulation bus in CANoe by the interface hardware provided by CANoe to achieve real-time CAN bus semi physical matter simulation, which is shown in Fig. 1.

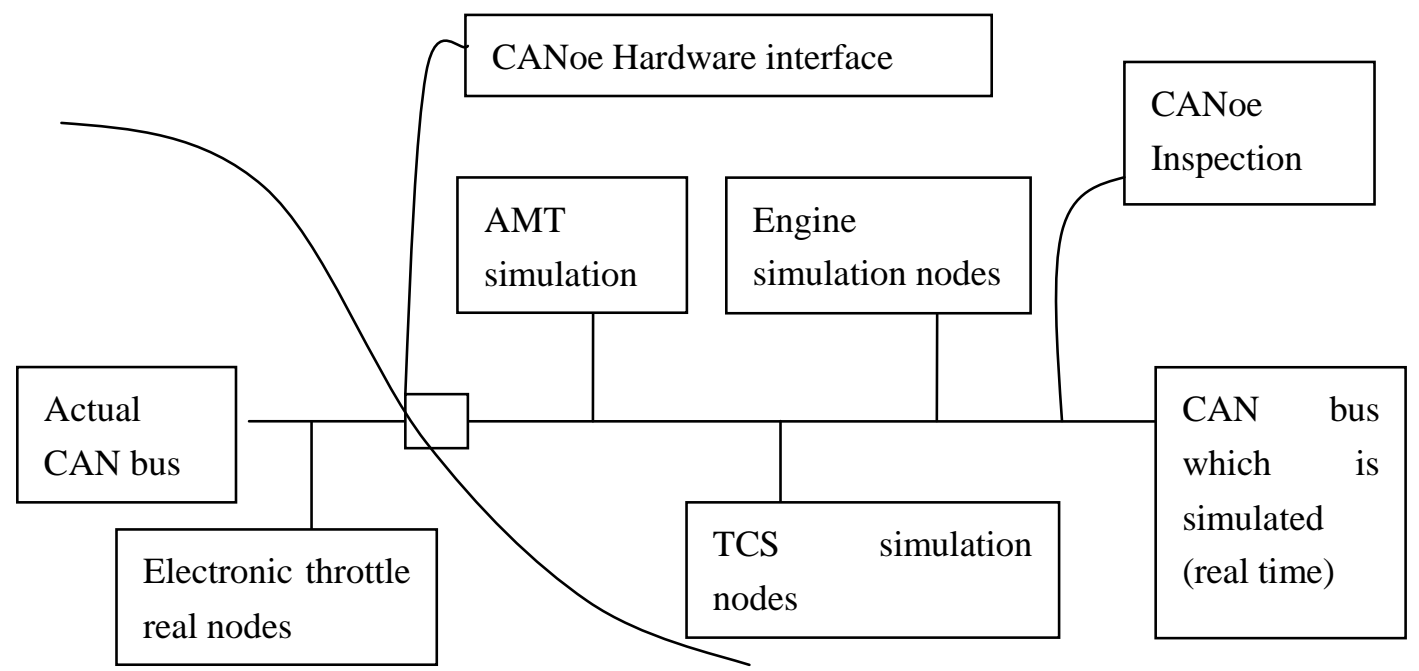

Figure 1. Semi physical matter simulation principle figure

In the scheme, an electronic throttle is added between engine and ECU and is connected to bus. TCS node and AMT node can indirectly control torque and rotational speed of engine by controlling the output of electronic throttle and verify the control effects and communication situation by the semi physical matter simulation. Other nodes will be designed and connected to actual bus according to the network protocol of the scheme design. The functions and communication performance shall be tested to complete the design of other nodes in the system and then to complete the design of the bus system.

\section{Conclusion}

Combining the research status and development trend of vehicle network technology and CAN bus protocol at home and abroad, taking a light vehicle as the target, this paper establishes CAN communication network for electronic controlled diesel engine, automatic mechanical transmission and traction control system. This paper also deeply studies and establishes the communication protocol, to achieve the joint control of engine output torque, transmission gear and driving wheel brake of electronic control system. The paper completes the off-line simulation, semi physical simulation and system integration test using CAN bus development tool CANoe and puts forward a set of feasible development process of electronic control system of CAN communication. The paper chooses SAE J1939 communication protocol according to the actual situation of vehicles and puts forward CAN communication scheme according to the functional requirements of driving force electronic control system: achieve the indirect control to the engine of AMT and TCS by adding electronic throttle nodes. 


\section{References}

[1] p. Discussion on "Progress in aircraft aerials" before the Electronics and Communications Section, 2nd April, 1962[J]. Computational Fluid Dynamics Principles \& Applications, 2001, volume 14(1):134-143(10).

[2] [No authors listed]. News Briefs: "Smart" electronics and communications technologies can substantially reduce greenhouse gas emissions. [J]. Environmental Science \& Technology, 1998, 32(19).

[3] Withers M J. Worldwide superbrain recognises electronics and communications [J]. Electronics \& Communication Engineering Journal, 1996, 8(5):202.

[4] Plonus M. Electronics and Communications for Scientists and Engineers [J]. Mechanical Engineering, 2001(10):93.

[5] Keller J. Military spending for electronics and communications stable after steep decline [J]. Military \& Aerospace Electronics, 2014.

[6] Breckon A. Marconi Electronics and Communications Technology (ECT) Project in Secondary Schools [J]. Journal of Design \& Technology Education, 2000, 5(3).

[7] Keller J. Defense Department would cut electronics and communications spending by 10 percent in 2012 budget [J]. Military \& Aerospace Electronics, 2011.

[8] Yoshikuni Y. Joint Special Section on Opto-electronics and Communications toward NGN and beyond [J]. Ieice Transactions on Electronics, 2008, E91C (7).

[9] Shin S. Electronics and Communications, A solution for Environmental Problem [J]. Eica, 2010, $15: 31-32$.

[10]Maciej J. Ogorzałek. Fundamentals of Fractal Sets, Space-Filling Curves and Their Applications in Electronics and Communications [M]// Intelligent Computing Based on Chaos. Springer Berlin Heidelberg, 2009:53-72.

[11]Mahesh B K. Varanasi (S'87-M'89-SM'95) received the B. E. degree in electronics and communications engineering from Osmania University[C]// Rice University. 2010.

[12] Savage P R. Patent watch [electronics and communications devices] [J]. Spectrum IEEE, 2005, 